\title{
Creative Economy: Guidelines for Developing LamPaTao's Community Enterprise of Sustainability "Tilapia" Transformation in Chaiyaphum Province, Thailand
}

\author{
Pramuk Srichaiwong \\ Panisara Hadkhuntod \\ Rajabhat Chaiyaphum University \\ Thailand \\ Pornchai Jedaman \\ Rajabhat Mahasarakham University \\ Thailand \\ Benjapuk Jongmuanwai \\ Rajabhat Nakhonratchasima University \\ Thailand
}

\begin{abstract}
The paper discusses an ability for managing and developing the model of community enterprises. It is to become a strong community economic system and able to developed to be an entrepreneur of a higher business unit. This show the preparation of creative economy in guidelines for developing Lam Pa Tao's community enterprise of sustainability "Tilapia" transformation of Chaiyaphum Province, Thailand. A main factor which affects the operation and is also its strength is to supporter of a province and government agencies serve. Weaknesses include marketing competence of Lam Pa Tao's community enterprise of sustainability "Tilapia" transformation, products' standard and distribution channel. The supporting of government agencies serveas their opportunity while competition is threat. Therefore, developing these producer groups follow the guidelines which focus on solving these weaknesses and enhancing their performance to become of strong and sustainable.
\end{abstract}

Keywords: Creative economy in guidelines for developing, Lam Pa Tao's community enterprise, sustainability "Tilapia" transformation.

\section{Introduction}

The development of community enterprises is a promotion of community economy, which is the basis of sufficiency economy development for allowing members to be promoted in local knowledge and wisdom, monetization, helping each other.[1] This can be said that community enterprise as the goal is to survive, not to be rich, but in order to survive and focus on sufficiency by mainly using community funds. [2] Including capital which is a resource of knowledge, wisdom, people, labor, social and cultural capital, emphasizing cooperation and supporting [3]. Raising "Tilapia" in floating cages is a form of high-yield farming and maximize economic benefits and use of general water resources, also helps those without land to turn to fish If releasing fish at an appropriate rate will result in a better growth rate, can help to shorten the farming time. [4]It is also convenient to manage the movement a harvesting and having less investment than other forms of farming. Raising "Tilapia" in floating cages there may be some disadvantages (e.g., the problem of parasitic diseases that cannot be controlled with water, environment, if without considering the quantity and location of the floating cage and the suitability of the river). therefore important principles to keep in mind for raising "Tilapia" in floating cages were the area for raising, the flow of currents, the depth of the water source and away from the disturbance [5] for promoting the integration of" Tilapia" transformation groups and joint management for increasing production efficiency in a complete cycle and linking to the marketing of sustainability, because "Tilapia" has a white, appetizing texture, there is still a good chemical structure, creates a gel that is as good as sea fish that is suitable for processing into a variety of food products. However, the operations of Lam $\mathrm{Pa}$ Tao's community enterprise of sustainability "Tilapia" transformation to still have problems in working that is lacking strength and sustainability, because the members of various product processing groups are still unable to operate on their own, if there is no good knowledge management system. Combined with the important problems not yet accepted standards, therefore cannot find a market to support the product clearly.

\section{Background of Study}


Is only production for household consumption and distribution in a small amount, therefore the group does not have a stable income and still cannot be completely self-reliant. Therefore, if the potential development to would allow the community to be able of self-reliant and developing a strong community economic system.

Also, one important way is to restructure the economy to a new direction of growth to focus on developing the internal economy to reduce dependence on external factors, and creating market value under the context of Lam Pa Tao's community enterprise of sustainability "Tilapia" transformation. This research in objective aimed to study of creative economy in guidelines for developing Lam Pa Tao's community enterprise of sustainability "Tilapia" transformation on fourth mains including business operations, factors affecting business operations, analyze the business situation, and setting the guidelines of creative economy in developing Lam Pa Tao's community enterprise of sustainability "Tilapia" transformation in Chaiyaphum Province, Thailand.

\section{Literature Review}

\section{A. Small and Micro Community Enterprise (SMCE)}

Small and micro community enterprise: SMCE is the word used after the Thai government has given importance to the sufficiency economy in parallel with the mainstream economy, because the mainstream economy creates a disparity between people's income and causing many different social problems. The community enterprises are small and micro enterprises into creative community capital management for self-sufficiency and sufficiency of families and communities. capital here is not just about money but also resources, products, knowledge, wisdom, cultural capital and social capital to achieve efficiency and sustainability, mainly for the community of the owner of that enterprise[1].It can be said that community enterprises are community affairs in relation to the production of goods, the provision of services, and other operations by a group of persons with ties, have a common way of life and gather to do business regardless of the form of juristic person and not being a juristic person for create income and for self-reliance of families, communities and between communities. Lam Pa Tao's community enterprise must operate in the manner of the wisdom of a community organization or a network of community organizations. [4] With community members owning production factors in terms of production, trade and finance, including the use of production and resources at every step for community learning for economic and social benefits. This is guidelines for developing Lam Pa Tao's community enterprise of sustainability "Tilapia" transformation in Chaiyaphum Province, Thailand.

\section{B. Creative Economy}

"Creative Economy" were the common elements of the conceptual to with creative issued to human resource under the knowledge including education, creativity, and intellectual property that are linked to cultural foundations, accumulation of knowledge and innovative technology into creative value and value [6]. The culture of "Tilapia" has been developed to be more commercial, with expanding the area of culture and has a tendency to increase continuously causing the business of "Tilapia" farming to be widespread in all regions of Thailand. Raising fish in floating cages is a form of high-yield farming resulting in maximum economic benefits. There are 2 types of "Tilapia" in farming were to; a) one-owner business model, b) contract farming with farmers to receive production inputs and the purchase of products by the company, for the single owner model, the farmers have to procure the inputs themselves. In research to study of creative economy in guidelines for developing Lam Pa Tao's community enterprise of sustainability "Tilapia" transformation in Chaiyaphum Province, Thailand.

\section{Methodology}

\section{Research Design}

A research was the qualitative research both to participatory rural appraisal for learning and development to applied from community analysis of participatory rural appraisal and transformative action and learning research of the instrument of creative economy in guidelines for developing Lam Pa Tao's community enterprise of sustainability "Tilapia" transformation in Chaiyaphum Province, Thailand including business operations, factors affecting business operations, analyzed the business situation, and setting the guidelines of creative economy in developing Lam Pa Tao's community enterprise of sustainability "Tilapia” transformation.

\section{Areas and Key Informants}

The areas in this study as Lam Pa Tao's Dam community enterprise include communities of Ban ThaKok and Ban Nong Phi Phuan in Chaiyaphum Province, Thailand. The key informants of participants including community leaders, groups of farmers raising "Tilapia" in floating cages, and housewife groups in the target village, who voluntarily joined the community enterprise of sustainability "Tilapia" transformation, totals fifty persons. Participants they all were purposive sampling and focus groups.

\section{Collection Methods}


The collection with in-depth interview by interview questionnaire of a structure and observation andgroup interview by interview questionnaire of un structure to collection as two areas in this study as Lam Pa Tao's Dam community enterprise with fifty key informants of the data were followed;

-Studying groups of farmers raising "Tilapia" in floating baskets, and housewife groups of the community enterprise of "Tilapia" transformation from studying general information and business operations in the area of management, finance and accounting, production and marketing into in-depth interviews of a structured interview with community leaders, groups of farmers raising "Tilapia" in floating cages, and housewife groups in the target village of the community enterprise "Tilapia" transformation. And participatory observation and group interview with "Tilapia" transformation groups.

- Studying factors affecting the business operations of community enterprises and producer groups by structured interview with community leaders, groups of farmers raising "Tilapia" in floating cages, and housewife groups in the target village of the community enterprise "Nilotic" transformation.

-Analyzed the business situation of community enterprise and the privatization group with an interview, the information obtained from the interview.

-Setting the guidelines for group development, in this regard, group development guidelines that group members jointly define will be the information for selecting the privatization group with the same objective.

\section{Data Analysis}

The purpose of data analysis on descriptive strategically, the qualitative data to analysis by using three main stages, i.e., data reduction, data organization, data interpretation to conclusion. Also,analyze the business situation of community enterprise and the privatization group with an interview, the information obtained from the interview is used to SWOTanalysis for identify strengths, weaknesses, opportunities, and threat.

\section{Finding and Discussion}

The purpose of creative economy in guidelines for developing Lam Pa Tao's community enterprise of sustainability "Tilapia" transformation in Chaiyaphum Province, Thailand were followed:

A. General information and business operations in the area of management, finance and accounting, production and marketing were followed;

1) Management in business operations of Lam Pa Tao's community enterprise to the past is in the form of a village committee, divided responsibilities into various departments including finance and accounting, production and marketing, which management is related to the production and distribution of processed products. by the operational plan according to the intention of the committee was aim to include all groups of manufacturers of processed products Under a single community enterprise.

2) Financial and accounting to initial capital to purchase some raw materials and equipment to received support from the province, in addition, the office of community enterprise promotion has given to the budget for the productions, but not enough for manufacturers to buy various raw materials. In the area of accounting is a form of posting income and expense records, and calculate the profit received monthly, the profits that have been collected are to be used as capital for the next production. For paying compensation to members who come to help in each production to be daily at the rate of 300 baht per day, also providing compensation from the distribution of goods at the rate of 10 percentage of the selling price. Financial and accounting data are summarized and released monthly and informed the general meeting to members. However, the revenue and profit from product sales there are not many and the course is not received because there are people who buy the products into the amount is limited of the villages and nearby villages only.

3) Products for focusing on tilapia processing products, member of the production department has knowledge and production skills through training, but lack of continuity in educating about packaging that can enhance the value of the product.

4) Marketing Tilapia processing products there is still no standard mark to prevent the product from being sold in large markets with many consumers. The business operation problems were the products of the group have not yet received various standards, finding a market to distribute products, and lack of management knowledge and packaging to create product value.

B. Factors affecting the business operations of community enterprises and producer groupsto consists of internal and external factors were followed:

\section{-Internal Factors;}

1) Ahelping a government agencies, especially in matters of finance and supporting materials and equipment. 
2) Knowledge and ability in product processing. Therefore, if members are able to produce products that are neat, beautiful, of good quality, they will add value to the product; customers are acceptable and able to compete in the market.

3)Knowledge and entrepreneurial ability of members because will help the group to do business well both to production and finance, accounting, marketing, management within groups, and making the group more competitive and able to continue to work to create stable income for the group.

4) The unity of group members due to the production to be each piece of work requires the cooperation of members to help in every step until the product is complete for sale. Also, helps to speed up work Increase the number of work pieces in a limited time.

5) Continuity in member operations due to affecting production capacity.

6) Machines, materials and equipment for production that are suitable enough to make of production quickly, and helping increase production capacity. And affect the quality of the product.

7) Products with standards have received various standard marks because it helps to raise the value of the product to be of quality that can be marketed more easily.

8) Marketing promotion with public relations through various media, including trade fairs, because it helps customers to better know the products of the group and increase the chances of selling products.

9) Distribution channels because it helps the group to distribute more products to customers.

\section{-External Factors;}

1) Assistance from government agencies That will help promote the group to have standardized products to given of marketing opportunities that make products known to customers and have more distribution channels.

2) Various social media because it helps increase distribution channels, and communication between members within the group that is convenient, fast, and cost effective.

The general information and business operations in the area of management, finance and accounting, production and marketing and factors affecting the business operations of community enterprises and producer groups to consists of internal and external factors. PornsakVanarat and Thera Rutirod[6] to said that most community enterprises are still experiencing production problems, for product advertisements, where members are product advisers and via social media, because a individual sales are the most concise communication tools to able to communicate directly one-on-one with efficiency to potential customers, the product advertising section via social media. It is a popular method nowadays because it is spread easily and quickly, has a low cost and can reach the target group anytime, anywhere. And can be used with all types of products and services. Anurak Atitkavin[7] the business readiness and commercial registration to should be developing the products of the group to receive the product certification mark. Products with standards have received various standard marks because it helps to raise the value of the product to be of quality that can be marketed more easily. also giving customers the confidence to decide to buy products of the group. And the marketing promotion with public relations through various media, including trade fairs, because it helps customers to better know the products of the group and increase the chances of selling products. Especially if having a chance to open a booth to allow customers to see the actual product groups can offer products directly to customers. Distribution channels because it helps the group to distribute more products to customers, wider market lead to sales volume will increase accordingly. Aissues that need to be developed were the potential for operation and competitiveness, production efficiency and creating product value, includeproduct standards to make the product be a product of one Tambon, one product and distribution channels.

C. Analyzed the business situation of community enterprise and the privatization group of Lam Pa Tao's community enterprise of sustainability "Tilapia" transformation by SWOT analysis to shown on table 1.

\begin{tabular}{|l|l|}
\hline Strengths & Weaknesses \\
\hline 1 . The community to support the operations & 1. The group members still lack the \\
of various groups, including group & knowledge and ability to operate in various \\
development. And product development brand & field such as marketing, accounting \\
and trademark names as well as help procure & systematically. \\
raw materials, packaging and produce product & 2. Products does not yet have a receipt \\
labels for the group. & number and various standard marks. \\
2. Members have unity in their operations. & 3. Packaging lacks beauty, distinct and \\
3. Knowledgeable members in raising tilapia in & unique. \\
floating baskets. & 4. Members to lack knowledge and ability to \\
4. The products have good taste and are & create suitable packaging. \\
clean and without any chemical additives. & \\
\hline
\end{tabular}




\begin{tabular}{|l|l|}
\hline Opportunities & Threat \\
\hline $\begin{array}{l}\text { 1. Customers in the community know the } \\
\text { products of the group. }\end{array}$ & $\begin{array}{l}\text { 1. The competitors are many products and } \\
\text { many of them have the certification mark and } \\
\text { 2. There are many communication channels } \\
\text { are OTOP products. }\end{array}$ \\
$\begin{array}{l}\text { distribution channels. } \\
\begin{array}{l}\text { 3. Organizing various activities of the province, } \\
\text { giving the group the opportunity to trade fairs. }\end{array}\end{array}$ & $\begin{array}{l}\text { afect of the production cos. } \\
\text { causes consument economic situation which }\end{array}$ \\
\hline
\end{tabular}

Table 1:SWOT analysis the business situation of community enterprise and the privatization groupLam Pa Tao's community enterprise of sustainability "Tilapia" transformation

D. Setting the guidelines for group development, in this regard, group development guidelines that group members jointly define will be the information for selecting the privatization group with the same objective to shown on table 2 .

\begin{tabular}{|c|c|}
\hline Development Issues & Guidelines to Development \\
\hline $\begin{array}{l}\text { 1. Groups potentially } \\
\text { 1.1 Certification of legal integration }\end{array}$ & $\begin{array}{l}\text { 1) Registration of community enterprises by } \\
\text { registering to combine only one. } \\
\text { 2) Registration as a manufacturer and the } \\
\text { entrepreneurs of one Tambon one Product } \\
\text { (OTOP). }\end{array}$ \\
\hline 1.2 The ability to operated & $\begin{array}{l}\text { 1)Training for product knowledge and skills. } \\
\text { 2)Training for accounting knowledge and skills. } \\
\text { 3)Training for marketing knowledge and skills. }\end{array}$ \\
\hline 1.3 Strength and sustainability & $\begin{array}{l}\text { 1) Knowledge management in community } \\
\text { enterprise groups. } \\
\text { 2) Encourage the community to participate in the } \\
\text { processing. }\end{array}$ \\
\hline 2. Efficiency in production and processing & $\begin{array}{l}\text { Procurement and purchase of materials sufficient } \\
\text { equipment for production and processing. }\end{array}$ \\
\hline $\begin{array}{l}\text { 3. Processing products } \\
\text { 3.1Product labels }\end{array}$ & $\begin{array}{l}\text { Designing and creating labels for attaching to } \\
\text { processed products. }\end{array}$ \\
\hline 3.2Product story & Compile product stories. \\
\hline $\begin{array}{l}\text { 3.3Product quality to receive community } \\
\text { product standards }\end{array}$ & $\begin{array}{l}\text { 1) Study and plan product development to meet } \\
\text { the criteria for considering community product } \\
\text { standards. } \\
\text { 2) Product development to meet the criteria for } \\
\text { considering community product standards. } \\
\text { 3) Submitting requests for certification of } \\
\text { community product standards. }\end{array}$ \\
\hline $\begin{array}{l}\text { 3.4 Being selected as one Tambon one Product } \\
\text { with a rating of four stars }\end{array}$ & $\begin{array}{l}\text { 1) Study and plan product development to meet } \\
\text { the selection criteria of one Tambon one } \\
\text { Product. } \\
\text { 2) The process for selection. }\end{array}$ \\
\hline 4.Marketing promotion & $\begin{array}{l}\text { 1) Production of advertising media. } \\
\text { 2) Public relations for groups and products. }\end{array}$ \\
\hline 5. Distribution & $\begin{array}{l}\text { 1) Increasing distribution channels into the } \\
\text { market and use to information technology. }\end{array}$ \\
\hline 6. Learning center & Location improvements to be a learning center \\
\hline
\end{tabular}

Table 2: Guidelines for group development.

The guidelines for group development, in this regard, group development guidelines that group members jointly define will be the information for selecting the privatization group with the same objective were to groups potentially, efficiency in production and processing, processing products, marketing promotion, distribution and learning center. BanditManenam [8] the guideline for group development, which the group members jointly define is an information for selecting the product manufacturer group, have registered for a community enterprise and want to develop the group into a progressive and sustainable community enterprise. 


\section{Conclusion and Implementation}

Creative Economy in guidelines for developing Lam Pa Tao's community enterprise of sustainability "Tilapia" transformation was registration of community enterprises of Chaiyaphum Province, Thailand. A main factor which affects the operation and is also its strength is to supporter of a province and government agencies serve. Weaknesses include marketing competence of Lam Pa Tao's community enterprise of sustainability "Tilapia" transformation, products' standard and distribution channel. The supporting of government agencies serve as their opportunity while competition is threat. Therefore, developing these producer groups follow the guidelines which focus on solving these weaknesses and enhancing their performance to become of strong and sustainable. Guidelines to development including registration of community enterprises by registering to combine only one, registration as a manufacturer and the entrepreneurs of one Tambon one Product (OTOP), training for product knowledge and skills, encourage the community to participate in the processing, 2) efficiency in production and processing of procurement and purchase of materials sufficient equipment for production and processing, 3)processing products of designing and creating labels for attaching to processed products, 4) marketing promotion to public relations for groups and products, production of advertising media, 5) distribution for increasing distribution channels into the market and use to information technology, and 6) learning center for Location improvements to be a learning center. Which the development of knowledge and understanding include process of preparing documents for producer groups into development to should encourage the community to participate in the operations of the producer groups in order for developing the capability of the operation, from the production operation according to the production plan specified by the members. And considering the need for products for use in various activities because production planning will enable businesses to produce quality products and create value efficiently.

\section{References}

Community Development Department. 2015. Manufacturer's operation manual and new OTOP operators. Bangkok, Thailand: Office.

KunyamonIn hang. 2011. Community enterprise management. Phitsanulok: Phitsanulok University, Thailand.

KanidaKaisanti and RasamonKumdee. 2016. Guidelines for potential development of the Sukavadee community enterprise group. $7^{\text {th }}$ national and international academic conferences. 7(6),p. 554-566.

Plunkett, R. W.,Attner, F. R., \& Allen, S. G. 2002. Management: meeting and exceeding customer expectations (7 th ed.). Cincinnati, OH: South-Western.

Collins, K. M. T. 2010. Advanced sampling designs in mixed research current practices and emerging trends in the social and behavioral sciences. in Abbas, T. (Ed.), SAGE handbook of mixed methods in the social \&behavioral research. Singapore: SAGE.2 nd ed., p. 357-377.

PornsakVanarat and Thera Rutirod. 2010. A planning for the development of rice mill community enterprise. Local Administration Journals, 2(4), p. 1-8.

AnurakAtitkavin. 2017.participatory OTOP product management Integrate into 4 to 5 stars. Journal of Management, Faculty of Management Science, Rajabhat Lampang University, Thailand, 7(2), p. 26-37.

Bandit Manenam. 2016. Success in the development of community enterprise, Ban Phon

PraewWa of Silk Weaving Group. Local Administration Journals, 2(4), p. 12-24. 